\title{
Meetings in north and south
}

\section{New Orleans, Louslana}

\section{\& Hobart, Tasmanla}

Bотн the American Association for the Advancement of Science (AAAS) and the Australian and New Zealand Association for the Advancement of Science (ANZAS) opened their annual congresses last week. Both chose to give most weight to the predictions and possible effects of global changes in climate; ANZAS with 'Global change and the South-west Pacific' as its theme, and AAAS with global change as one of the three broad areas into which the conference was divided.

Both conferences were also marked by disappointing attendance figures. ANZAS in Hobart attracted only 700 people and AAAS in New Orleans around 6,000 , including the 500 press, 1,000 speakers and many high-school students who attended special events. Part of the problem is location; neither Hobart nor New Orleans has a large local scientific community. At San Francisco last year, AAAS drew 10,000 people.

Scientists in both nations rehearsed gloomy scenarios to accompany possible global temperature rises but only the Australians managed to find a little cheer amidst the predicted mid-twenty-firstcentury disappearance of the Marshall Islands and Tuvalu beneath the rising seas.

Barrie Pittock, from the Commonwealth Scientific and Industrial Research Organization (CSIRO) Division of Atmospheric Research in Melbourne, estimated that US grain exports, which account for 50 per cent of the international market, would be hit by severe drought. But global warming would boost grain production in all Australian states except Western Australia, providing Australia with a chance to increase exports.

Both conferences had their share of eccentricities and disagreements. As talk titles go, ANZAS wins the prize for "Premises for the feasibility of motors using principles of psychokinesis". In New Orleans, the debate over the role of Albert Einstein's wife, Mileva Maric, in the formulation of the theory of relativity looks set to run and run.

At AAAS, a session on cold fusion could still pack a room and leave a small crowd listening at the door, but it was no longer scientific miracles that people were there to hear. The cold fusion affair is already a case study and the speakers were two sociologists, two historians and one physical scientist. The National Science Foundation announced that it is assembling a cold fusion database at Cornell University to record the event and its backlash. Already more than four cubic feet of electronic mail messages, laboratory and lecture notes, press clippings and records of press conferences have been assembled.

Other than the many aspects of global change, half a dozen topics among $200 \mathrm{odd}$ sessions spread over five days were considered weighty enough for a full day of talks at AAAS. Human sexuality and sexual behaviour was one of them, and the results of new US national survey by Tom Smith of the University of Chicago drew a packed house. To everyone's surprise, Smith found that US adults are far more puritan than previous surveys and anecdotal evidence would suggest.

According to the survey, 22 per cent of Americans were abstinent last year, and only 1.5 per cent had an extramarital affair. "Chaste" adults who had never had sex with anyone other than their marriage partner account for nearly half the population.

Less than 1 per cent of adults are exclusively homosexual, and only 1.5 per cent reported any homosexual contact in the past year. The homosexuality figure is nearly an order of magnitude lower than previous estimates. Although the study sample size was just 1,400 , the data suggest that only 6.8 per cent of the population is at a relatively high risk for AIDS infection, Smith says.
Another full day went to the use of animals in biomedical research, with AAAS taking a tougher stand as an advocate for animal research. Frederick Goodwin, head of the Alcohol, Drug Abuse and Mental Health Administration, says that there has been a serious decline in the number of papers published in which primates are used for drug addiction research, the area that has been one of the biggest targets of the animal rights movements.

The most powerful message came from Steve Carroll of Incurably Ill for Animal Research. His own life was saved after a plane crash as a result of medical advances made through animal research and he now runs a group that tries to publicize the benefits of medical research.

But among researchers, discussion of a moral position appears to be only just beginning. Animal rights campaigners are much more sophisticated and Goodwin estimates that they have $\$ 50$ million a year to spend on attacking the use of animals in biomedical research alone. Most of the money is raised in direct mail campaigns. Goodwin promised to get tough with institutes that did not protect their researchers, saying that he may have to examine grants to those that bow to pressure from animal rights campaigns.

Tania Ewing, G. Christopher Anderson \& Alun Anderson

\section{POLAR RESEARCH}

\section{French plan new initiative}

\section{Parls}

Ат a cabinet meeting last week, research minister Hubert Curien and Louis Le Pensec, the minister for overseas departments, offered new proposals to reorganize French polar research. An interministerial communiqué argues that the importance of the polar regions for the study of climatic change, astronomy and, in the Antarctic, the ozone layer, requires France to increase its activities.

In 1989, France spent FF110 million (\$19.3 million) on polar research, about half of what Britain or West Germany spent. At present, French polar research is concentrated in the Antarctic, with a single base under the administration of the TAAF (the French Austral and Antarctic Territories), a government body not geared to research. Under the new plans, an 'Institute for Polar Research - Paul Emile Victor Expeditions' will be set up with interests in both polar regions.

Initially, the institute will be financed out of the existing budget for polar expeditions but in the medium term research money will be diverted from the TAAF, together with an extra FF10 million per year for Arctic research from the research ministry. The long-term goal is to attract private sponsorship to transform the institute into a charitable foundation.

Two new interministerial committees will be established. One will make strategic decisions and will decide the main budgetary priorities, while the second will be a polar environment committee for ensuring "the compatibility of research activities with environmental conservation, in keeping with the position adopted by France during the fifteenth consultative conference on the Antarctic Treaty in Paris last October".

Although one goal of the new proposal is to coordinate research in both polar regions under a single administrative banner, most interest will still reside in the Antarctic. The present summer base at Dumont d'Urville is, says the report, "running out of breath". A second base, $1,000 \mathrm{~km}$ inland, is planned for 'Dome C', a 3,200-metre-high plateau near the South Pole and directly under the hole in the ozone layer. Dome $\mathrm{C}$ is in the Australian Territory and the French nope to use the abandoned infrastructure of a previous US camp there.

The base will be the third inland station, along with the US South Pole base and the Soviet Vostok base in the Antarctic highlands, and will allow 15 scientists to winter on the continent.

Peter Coles 